The laboratories of the Association are equipped with instruments for research in textiles and allied fields. Some of these instruments have been designed and fabricated there. The physies laboratory has equipment for studying the structure and physical and mechanical properties of fibres, yarns and fabrics. The chemistry laboratory has, in addition to the usual facilities for analysis of textile materials, a unit processing section equipped for the treatment of samples of yarns and fabrics through processes such as bleaching, dyeing, printing and finishing. The pilot mill is a versatile unit and its machinery offers a wide range of processing sequences in spinning, weaving and chemical processing. The workshops are equipped for the dual purpose of servicing mill machinery and of designing, fabricating and servicing laboratory instruments.

The Association owes its success in large measure to the enthusiasm of its workers. Most of these workers have been recruited from universities and initiated into specialized fields of industrial research. When necessary, training has been supplemented by periods of study in overseas institutions. Technical assistance schemes such as the Point Four Programme, the Colombo Plan and the Imperial Chemical Industries Fellowships have been of great value. From a small group of about twenty-five workers in 1949, the Association has developed into an organization with a total strength of 200 , which is made up of 75 scientists and technologists, 25 administrative workers, 40 skilled operatives and 60 service personnel.
The services of a number of foreign specialists have been secured from time to time with the assistance of organizations like Unesco and the International Labour Organization; in 1956 the Association was recognized by Gujarat University as a teaching centre for postgraduate research. At present most of the research students are awarded scholarships or fellowships by the Government of India, the Council of Scientific and Industrial Research, Gujarat University and the Association.

In a technologically under-developed country, it is often the path of least resistance to apply to one's own use the findings of more advanced countries. During the early days, the Association emphasized the application of scientific and technical knowledge already available to the problems of the industry. This practice of helping the industry to implement the findings of research has paid rich dividends and constitutes one of the main activities of the Association. at present. In the process, industry has become wide awake to the potentialities of original research and has cordially welcomed the Association's efforts.

While being primarily a research organization the Association tries to help industry in other ways. Training in various skills, such as management and supervision, statistical methodology and testing procedures, is given to the staffs of member mills. Such trained personnel not only become better equipped for their work, but also help in securing more effective implementation of the Association's programmes. Often, they form the nucleus of research and training groups in their own organizations.

\title{
GLASSHOUSE CROPS RESEARCH INSTITUTE
}

$\mathrm{T}$ 'HE annual report of the Glasshouse Crops Research Institute for $1957 *$ shows that, although full facilities are not yet available, the physical development of the Institute has made good progress and some of the major problems associated with com. mercial glasshouse practice have been investigated. Physiological studies of the growth of tomatoes have continued, and practical problems of plant spacing and pruning have received attention. Previous studies at Cheshunt and the Institute havn shown that retention of lateral branches below the first truss, on widely spaced plants, of the variety 'Potentate' gave a yield nearly three times as great as on single-stemmed plants. It was of importance to discover whether this constituted an increase in yield per unit area of glasshouse space, the factor of most concern to the grower. This has been investigated in preliminary experiments by comparing the yields from plants having no side shoots and plants in which side shoots below the first truss had been allowed to develop. Three different spacings between the rows were used. The greatest yield per unit area was obtained from single-stemmed plants at the two closest spacings, namely, $2 \mathrm{ft}$. and $3 \mathrm{ft}$., although multistemmed plants at $3 \mathrm{ft}$. and $4 \mathrm{ft}$. spacings had the greatest mean weight of individual fruit. No treatment had any effect on weight per unit area of early fruit.

A review of the literature on spacing of tomato plants in commercial cultivation, included in the report, shows that there is no simple answer to the * Glasshouse Crops Research Institute. Annual Report 1957. Pp.
161. (Littlehampton: GIasshouse Crops Research Institute, 1958.) 10s. question of optimal planting density for maximum yield. It is thought that this may be because in. sufficient attention has been given to possible interactions between planting density and watering and manuring. The study of the composition of the tomato fruit has been continued by the Chemistry Department, especially in relation to variety and state of ripeness of the fruit, with special reference to fruit quality and ripening disorders. It was concluded that the latter, evident by their effects on the outer fruit wall, were also related to the composition of the inner portion of the fruit. Further investigations were made of the changes during ripening. The acidity in the wall increased from the green stage to the first appearance of yellow pigmentation, but there was no consistent trend as ripening proceeded. This was in contrast to the situation in the inner portion of the fruit, where acidity decreased and sugars (mainly glucose and fructose) increased. The concentration of soluble solids in the expressed sap of the tomato varies considerably in relation to fruit quality and variety. These investigations will be facilitated by the demonstration that measurement of refractive index by a simple hand refractometer gives a reliable indication of total dissolved solids.

Work on urea-formaldehyde compounds as slowacting nitrogenous fertilizers has been concluded, and a report gives the relative merits of the several compounds tested. Liquid feeding of tomatoes is of considerable topical interest, especially in connexion with automatic irrigation, and research on this problem has been resumed. Magnesium deficiency 
in glasshouse tomatoes is common, and preliminary results indicate that foliar sprays containing magnesium are more effective than soil treatments in maintaining normal leaf colour. The plant-breeding programme is concerned mainly with improvements of tomato, cucumber and lettuce.

The investigations on Didymella stem rot of tomato have been continued by the Plant Pathology Department, which is also concerned with powdery mildew of cucumber and wilt disease of carnation as well as mushroom diseases. Some experiments were carried out on chemotherapeutic control of tobacco mosaic virus in the tomato, but it was concluded that this approach is not promising. Although insecticides properly applied should give adequate control of white fly, there are sometimes risks of chemical injury to plants, and for this reason interest has been revived in the method of biological control by wasp parasites. The Entomology Department has begun a series of studies on the effects of environmental factors on the fecundity and development of white fly and on the host/parasite balance. Other investigations by this Department include mushroom pests and the red spider mite. The Crop Protection Department is concerned with the control of mildew of chrysanthemums and aphids on lettuce and with the residual toxicity of certain sprays.

E. C. Humphries

\section{RADIOLOGICAL HAZARDS TO PATIENTS}

$\mathrm{A}^{\mathrm{T}}$ $T$ the end of 1956, the Secretary of State for Scotland and the Minister of Health appointed a committee "to review the present practice in diagnostic radiology and the use of radiotherapy in nonmalignant conditions, having regard to the report of the Committee on the Hazards to Man of Nuclear and Allied Radiations".

This committee, under the chairmanship of Lord Adrian, has now produced an interim report (Ministry of Health; Department of Health for Scotland. Radiological Hazards to Patients : Interim Report of the Committee. Pp. 22. London : H.M. Stationery Office, 1959. 1s. $3 d$. net) for the one completed part of its survey, namely, the use of $\mathrm{X}$-rays for mass miniature radiography. The conclusion is drawn that, when properly conducted, examinations by this method make a negligible contribution to the total radiation to which the population is daily exposed. Even on the most pessimistic assumptions, the indefinite continuation of mass miniature radiography at the present rate could add no more than 20 cases of leukæmia to the annual incidence of 2,500 cases in Great Britain ; it is also possible that it would produce no additional cases at all. The gonad doses, which determine the long-range genetical damage, have been found to be even smaller than previously estimated. These very small somatic and genetical risks have to be considered in relation to the undoubtedly large benefits of mass miniature radiography to the health of the population. In 1957, these examinations led to the discovery of nearly 18,000 cases of pulmonary tuberculosis and some 63,000 other abnormalities, which included lung cancer, heart disease and pneumoconiosis. For children and pregnant women, mass miniature radiography is not recommended and should be replaced by normal radiographic procedures with strict limitation of the field to the chest. Some general principles are also given for reducing unnecessary exposure in other forms of diagnostic radiology, in particular fluoroscopy; but the survey of this area is not yet completed.

There is one statement in the introduction (paragraph 10) which may give rise to serious misunderstandings. It is stated, correctly, that a dose of radiation which would double the present mutationrate would cause perceptible damage to the population, and that this dose is estimated to lie between 10 and $100 \mathrm{r}$. per generation. It is also correct to say that at present the dose due to medical radiology does not exceed 3 rads per generation. But it is only for the sake of convenience that genetical damage is usually estimated in terms of the 'doubling dose'. There is no lower threshold to the genetical effects of ionizing radiation, and serious genetical damage will be produced already by doses which are far below the doubling dose. In fact, the report of the Medical Research Council came to the conclusion that, from the point of view of genetical hazards, "the upper limit, which future knowledge may set to the total dose of extra radiation which may be received by the population as a whole, is not likely to be more than twice the dose which is already received from the natural background; the recommended figure may indeed be appreciably lower than this". On this evidence, the danger limit has already been reached or even exceeded in countries where $\mathrm{X}$-rays are used extensively for medical purposes. Against this damage to future generations we must, however, set the benefit to the present one and, although all means must be used to cut down avoidable exposure to radiation, a high amount of exposure will remain unavoidable if the present standards of medical service are to be maintained.

\section{FEEDING THE HUNGRY}

$\mathrm{T}$ HE practical way to wage war on want was the theme of an outstanding address at St. John's College, Annapolis, Maryland, on April 9 by $\mathrm{Mr}$. Gerard Piel, publisher of The Scientific American. Following an account of the way in which science has given man unlimited power and opportunities to change the material conditions of life, Piel shows how it is now possible to bring the elimination of want within the reach not only of the present generation but also of all future generations. Want is no longer a challenge to technology, but to economics and politics; it is a social problem. Thanks principally to the control of mortality, the underprivileged peoples are living longer and feeling well enough to do something about their plight. These aroused people are still extracting the irreplaceable resources of their lands to feed the voracious appetite for raw materials of Western peoples. At present the 